\title{
Fashion and New Luxury Digital Disruption: The New Challenges of Fashion between Omnichannel and Traditional Retailing
}

\author{
Simone Aiolfi ${ }^{1} \&$ Edoardo Sabbadin ${ }^{2}$ \\ ${ }^{1}$ Adjunct Professor of Marketing, Department of Economics, University of Parma, Italy \\ ${ }^{2}$ Professor of Marketing, Department of Economics, University of Parma, Italy \\ Correspondence: Prof. Simone Aiolfi, Department of Economics, University of Parma, Via J. F. Kennedy 6 - \\ Parma, Italy. E-mail: simone.aiolfi@unipr.it
}

Received: May 15, 2019

doi:10.5539/ijbm.v14n8p41
Accepted: June 10, 2019

Online Published: July 7, 2019

\begin{abstract}
The digital transformation has changed the rules of the game even in the world of fashion, luxury and fast-fashion retail. The fashion system today faces the challenge of renewing business models to intercept changes in purchasing and consumption behavior. Competition is played in the ability to create multi and omnichannel business models. The present work, after a careful analysis of the literature and the changes that have taken place in the fashion world, aims to study some innovative business models in the fashion system and in particular to investigate the perspectives of the physical store threatened by the digital transformation. The research offers points for reflection on the future of omnichannel fashion retailing. Will technology be able to create value for new consumers in the future? Moreover, from the retailers' perspective, case analysis will clarify which technologies are characterizing fashion sales points with the best performances in Retail 4.0. Finally, a section will be dedicated to the presentation of a theoretical framework on the adoption of omnichannel fashion retailing figured out through a review of the literature and managerial implications.
\end{abstract}

Keywords: digital disruption, fashion, luxury, mobile, omnichannel, online-offline retailing

\section{Introduction}

The distribution channels are in a phase of radical change. The success of the online channel and digitalization, driven by a few leading companies in recent years, have drastically changed the way people live and are changing purchasing patterns. The new technologies have multiplied the touch points, the broadband connectivity has increased the "always on" consumers, and at the same time, the online purchases (Pentina \& Hasty, 2009). In particular, mobile commerce has recently accelerated.

What are the implications of digital technological innovations? Will the physical store continue to play a key role? Will the online purchases be able to offer an engaging and exciting experience to the consumer?

The integration of e-commerce with physical channels creates opportunities and synergies: companies can offer multiple services through different channels and for different target segments. Internet retailing is creating greater value for the customer in terms of additional services and additional touch points.

To address these technological improvements, many retailers have developed multi-channel strategies by adding new touch-point channels to their portfolios through which companies can interact with consumers (Verhoef, Neslin \& Vroomen, 2007). To manage the new competitive logic and establish a long-lasting relationship with consumers, retailers have begun to manage the customer experience and integrate the retail mix levers of all distribution channels (Neslin et al., 2006). The major grocery retailers have become multichannel and the most dynamic ones are oriented to offline online integration and to omnichannel (Rigby, 2011), with the aim of providing consumers with more engaging, comfortable and uninterrupted experiences. Research on the new omnichannel retailing paradigm is still limited, in particular, research on omnichannel fashion retailing.

\section{Omnichannel Retailing and Retail 4.0}

The literature hypothesized a clear distinction between physical channel and online channel, but the recent integration of the channels led first to the study of multichannel (Lazaris \& Vrechopoulos, 2014) and then to omnichannel (Verhoef, Kannan \& Inman, 2015). However, the new paradigm has still different meanings: it can 
refer to a survival strategy (McCormick et al., 2014), to a unique "seamless" operation (McCormick et al., 2014) or it can indicate a service designed for consumers available anywhere and at any time (Fairchild, 2014). Today, consumers consider sales and marketing channels as a single entity, and the shopping experience is experienced without interruption regardless of the type of channel used (Herhausen, Binder, Schoegel \& Herrmann, 2015). In fact, omnichannel consumers use many or all of the available sales channels simultaneously during the purchase process: online channels, mobile devices and physical stores (Rosenblum \& Kilcourse, 2013; Lazaris \& Vrechopoulos, 2014). Omnichannel retailing conceptualizes the integration of all digital and physical channels (Rigby, 2011; Klosek, 2012; Frazer \& Stiehler, 2014). Omnichannel management provides, therefore, a synergic management of the touch-points in order to optimize the consumer experience (Herhausen et al., 2015). Often the terms multichannel and omnichannel are considered synonymous. However, the literature considers omnichannel retailing as a new paradigm. It is considered the set of activities involved in the sale of goods or services through all the channels activated at the same time with complete interaction by consumers and a full integration controlled by the retailer (Beck \& Rygl, 2015).

Since 2010, cross channel and above all omnichannel strategies have spread and, at the same time, literature has begun to investigate the challenges of their implementation (Bell, Gallino and Moreno, 2013; Brynjolfsson, Hu \& Rahman, 2013; Lewis, Foster \& Whysall, 2013; Strang, 2013; Beck \& Rygl, 2015). Researchers sought to clarify the challenges retailers face (Herhausen et al., 2015) and to analyze the implications for supply chain partners too (Brynjolfsson et al., 2013). The resources are moving towards the goal of creating a unique and personalized shopping experience. The new omnichannel strategies are directed towards a more intelligent, integrated and creative use of technologies. Desai, Potia and Salsberg (2012) have defined the new frontier as Retail 4.0. In an omnichannel context, the physical and digital virtual worlds are integrated and oriented towards hybrid solutions: the consumer can buy online and withdraw in store, can choose a product in the store and if this is not available he can order it online, he can buy online and return the product to the store. Retail 4.0 physical stores are increasingly connected and offer customers various formulas to search online for information: tablets, interactive totems, mirrors and interactive walls, virtual dressing rooms, mobile apps and live chat. In addition, retailers can use RFID, Qr-code and beacon labels that allow them to send personalized messages to consumers and manage the relationship in order to better understand consumer behavior. The creation of a unique shopping experience is one of the priorities of fashion and luxury brand retailers who are therefore forced to adopt an omnichannel approach and to manage the physical and digital dimensions of retail phygital (Armstrong \& Rutter, 2017).

\section{The Rise of Omnichannel Fashion Retailing: Insights}

Consumers increasingly informed and omnichannel, in the fashion sector increasingly attach importance to the experiential and emotional dimension of the shopping experience. The fashion retailers, after seasons focused on the opening of physical stores, have begun to develop new virtual spaces. Fashion, with $28 \%$ growth in 2017 (2.5 billion euros) is one of the leading sectors of Italian e-commerce, preceded only by tourism, information technology and consumer electronics (Osservatorio eCommerce, 2017). The challenge for fashion retailers is to manage all the touch points and guarantee a unique brand experience that is consistent with the brand's values. Indeed, digital transformation is not just e-commerce but also a dynamic website, presence in social networks and app development. The integration of digital technologies in store is another priority for fashion retailers; the physical store, to continue to play a crucial role in the mind of the customers and avoid cannibalization, must evolve from a simple place of sale to an environment in which to live a rewarding shopping experience.

Fashion brands today understood the importance of online, but are struggling to communicate their values via the web with respect to what happened in the boutiques of the physical channel. This is one of the causes of the digital delay of the fashion system (Keller, 2008; Kapferer, 2017). The intrinsic characteristics of luxury goods such as prestige, excellence in quality, exclusivity, symbolic meaning, emotional involvement and high price seem to clash with the founding principles of online channels and the Internet, namely democracy and accessibility (Dubois \& Duquesne, 1993; Kapferer, 2017).

Literature has debated the attempt by fashion and luxury retailers to get out of what has been defined by Kapferer (2017) as "Internet Dilemma": on the one hand, the Internet is struggling to transmit sophistication, quality and emotional involvement, risking to trivialize the perceived value of fashion products; on the other hand, the online channel is also a powerful communication vehicle, allowing information to circulate more freely and quickly, reaching a large number of current and potential customers. Integrating offline and online allows retailers to enhance brand awareness and brand reputation (Aiello \& Donvito, 2006).

Despite the advent of omnichannel fashion retailing, recent studies show that fashion stores continue to be a 
fundamental touch point for consumers. From a recent research by Forrester Research (2017) it emerges that in the fashion system both physical and digital stores play a fundamental role. The increase in online sales favors in-store purchases, confirming literature studies on the emergence of two opposite phenomena in an omnichannel context, showrooming and webrooming (Verhoef et al., 2007). Usually those who opt to buy online, even in the case of luxury goods, do so for convenience, convenience, for the presence of a wider assortment or for the possibility of customizing the purchase. On the contrary, those who prefer to buy in the traditional store do so because they want to touch the product before buying, as well as because they are afraid of counterfeit products or because they are buying luxury goods for the first time. Data on online sales, however, show that it is essential for fashion and luxury retailers to adopt an omnichannel approach.

Burberry is considered the pioneer of omnichannel fashion retailing and the complete integration of digital marketing in the fashion world. Angela Ahrendts, Chief Executive of Burberry from 2006 to 2014 was the promoter of the digital revolution of Burberry transforming the historic brand, always focused on elegance and English tradition, in a real Digital Luxury Retailer, enhancing its identity and the image. The success of Burberry in the online was confirmed by the Fashion Digital Index ranking drawn up by L2Inc which in 2015 named it the "Genius" of digital (L2inc.com, 2015). Burberry's omni-channel approach was driven by a desire to increase brand awareness, customer loyalty and consumer engagement. For these reasons Burberry decided to develop a social channel and an e-commerce site characterized by a very high quality of images and digital contents, the possibility to customize garments, to buy online and collect in store, to enjoy a service assistance via live chat and customer service. Unlike other fashion and luxury retailers, Burberry in offline boutiques wanted to offer its customers an experience similar to that experienced in the online channel. The Burberry flagship stores, and in particular the one on Regent Street in London, are technologically advanced and equipped with huge digital screens that project exclusive videos linked to the brand, live-streaming of events and catwalk shows. Burberry has also created the "Burberry Retail Theater" with live shows that are streamed in stores around the world (Burberry.com).

The fashion sector has seen in recent years the proliferation of e-commerce sites managed by pure player specialists who sell exclusively online to which many fashion and luxury brands entrust the management of the sales of their collection. Armani, Dolce \& Gabbana and Moncler rely on Yoox to manage the single-brand online channel, others at Net-a-porter and Mytheresa.com, as did Prada and others at Asos, Privalia, Zalando, Luisaviaroma.com and Amazon. Other retailers decide to develop single-brand e-commerce sites, especially fast fashion and mass market retailers such as OVS, Oysho, H\&M, Zara and Bershka. Interesting however is the proliferation of luxury brand e-commerce sites such as Gucci (the first to open the site in 2002), Armani, Chanel, Versace, Dolce Gabbana and Prada who understood the potential opportunities of the online and started to consider the online channel as a real alternative means of entertainment, so as to make them become places of leisure and enjoyable leisure time, also used to watch the catwalks of the few events put online, overcoming the actual exclusivity of the fashion shows.

The introduction of Fashion Social Networks and Fashion App by the major fashion retailers that are managing social media through digital marketing strategies is also interesting. The development of Fashion App is an alternative way to encourage the development of an interactive relationship with the brand, facilitate the search for information, accompany the consumer during his purchase process by providing answers in every place and at any time, favor the purchase of the product directly from your smartphone or tablet, favor the creation of personalized promotions, develop personalized caring actions in the post-sales phase and implement loyalty programs.

\section{The Implementation of Omnichannel Fashion Retailing: Managerial Challenges and Implications}

In this section, we present the theoretical framework on the adoption of omnichannel strategies and the key drivers that led fashion retailers to adopt omnichannel strategies and new challenges for a correct implementation. The proposed framework combines the theoretical bases emerged from the literature with ideas obtained from research on the success cases of the fashion system companies. To address this issue we started from two research questions that guided our review of the literature, as well as the theoretical framework proposed in Figure 1.

Q1) What are the key factors that have stimulated retailers (and brands) to develop an omnichannel strategy in the fashion world? 


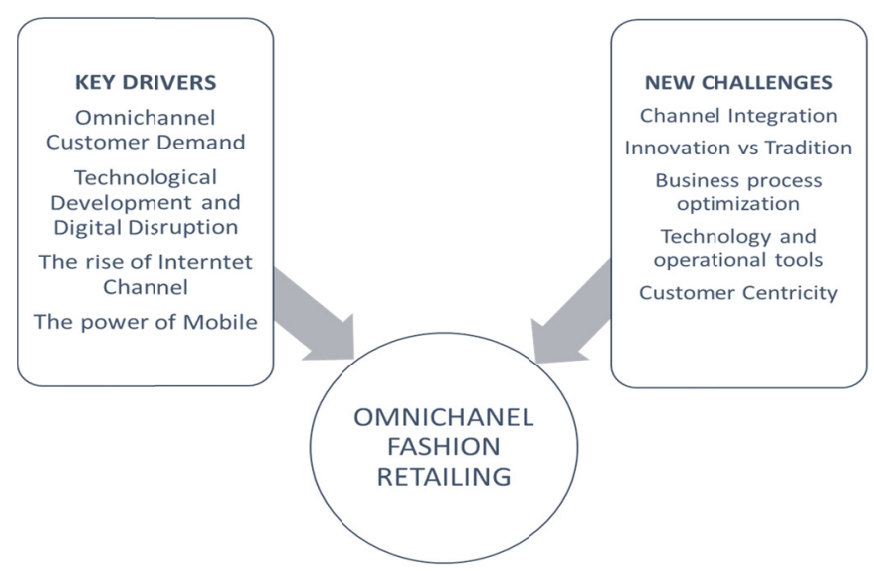

Figure 1. Theoretical framework of omnichannel fashion retailing implementation

Q2) What are the challenges that fashion and luxury retailers have to face when they decide to integrate an omnichannel strategy into their marketing strategies?

\subsection{Key Drivers of Omnichannel Fashion Retailing}

\subsubsection{The Omnichannel Consumer}

The consumer, today, is oriented towards omnichannel, he/she has not abandoned physical stores, he/she makes his/her own decisions moving between online and offline. Currently, the individuals are "always on" that means they are constantly connected wherever they are. Internet, smartphone development, the success of social media and social networks have changed consumer behavior. The customer journey is no longer linear and with reference to the fashion and luxury sector, omnichannel consumers are increasingly informed, complex, with little time, however they expect to have an ever wider selection of products, available at all times and everywhere (Piotrowicz \& Cuthbertson, 2014; Altagamma, 2018). Even luxury-oriented segments have become more attentive to price, promotion and better service. The simultaneous use of online and offline channels makes it easier to compare products and promotions (Brynjolfsson et al., 2013; Strang, 2013). Among the reasons for the purchase of luxury goods, the ostentation has lost importance compared to the positive experience (Altagamma, 2018). The post-modern consumer increasingly bases his/her purchases on the advice of relatives, friends and colleagues. Since 2010 the role of the influencer has grown, having gained official recognition throughout the fashion sector.

\subsubsection{Technological Development and Digital Disruption}

Omnichannel fashion retailing is driven primarily by technology (Oh, Teo \& Sambamurthy, 2012). In recent years, literature indicates that we are entering the era of so-called "digital disruption" (Schmidt \& Cohen, 2010), a term coined by Clayton Christensen (2006). The new technology produces a radical change in existing business models. The "digital disruption" literally "destroys" the "old" business models but at the same time is able to reward the new "digital forces", allowing the creation of benefit for all stakeholders. Technological innovations have changed the shopping activity; consumers now have smartphones, tablets, innovative software, mobile applications, innovative payment instruments, coupons and digital flyers as well as beacons, location-based services and augmented reality (Rosenblum \& Kilcourse, 2013). Companies try to integrate technological innovations and renew the layout of the stores with a view to optimizing the physical concept in order to guarantee a much more complex and engaging shopping experience (Rosenblum \& Kilcourse, 2013).

\subsubsection{The rise of the Internet Channel and the Power of Mobile}

The dependence on smartphones has become a global phenomenon. Today, people spend most of their daily lives on smartphones and mobile devices. Millions of consumers monitor their smartphone constantly, day and night, while they are with family or friends, during a business meeting and while driving (Bellini \& Aiolfi, 2017). The increasing penetration of mobile devices and the widespread mobile connectivity have changed the decision-making process of consumers and consequently their buying behavior. Consumers use mobile for 
different purposes: search for information on the web, planning the shopping expedition before entering the store, creation of a shopping list, price comparison, purchase of goods and services, post-purchase activities (Shankar, Venkatesh, Hofacker \& Naik et al., 2010; Bellini \& Aiolfi, 2017). The existing literature considers mobile technologies a resource to help consumers make better decisions, reducing research costs and improving the quality of consumer choice (Sciandra, 2014; Bellini \& Aiolfi, 2017). The mobile has the same advantages as the online channel, with further advantages for the nature of smartphones. Mobile devices allow consumers to buy online and offline in an innovative way through an immediate price comparison, reading reviews from other customers and evaluating non-digital components in the physical point of sale (Piotrowicz \& Cuthbertson, 2014).

Due to the rapid growth of the mobile channel, supported by the ease of use of the internet, in recent literature numerous researches on mobile marketing strategies have appeared. Researchers have identified several mobile marketing practices, such as mobile communication, targeted mobile couponing, email and messaging, mobile website creation and management, mobile word of mouth, mobile social network management, mobile customer care and mobile shopping (Shankar \& Balasubramanian, 2009; Shankar et al., 2010; Strom, Vendel \& Bredican et al., 2014). Fashion retailers and luxury brands are projecting themselves into the future by introducing visible, readable and manageable content for all mobile users and developing mobile fashion apps and social networks (Brynjolfsson et al., 2013).

\subsection{New Challenges in the Implementation of Omnichannel Fashion Retailing}

\subsubsection{Opportunities and threats of Integration Between Channels in the Fashion Sector}

The literature underlines two basic approaches for the integration between channels that can therefore occur both from the physical to the Internet and from the online towards the offline (Herhausen et al., 2015). To integrate online functions within offline channels, fashion companies provide self-service totems, virtual fitting rooms or kiosks with online assistance within physical stores (see Louis Vuitton, Pinko, OVS and Zara). This type of integration can reduce the negative effect for consumers of the unavailability of products in the physical store and provide increasingly personalized services (Bendoly, Blocher, Bretthauer, Krishnan \& Venkataramanan, 2005). To integrate offline functions in online channels, fashion companies provide consumers with a store locator with information on the various physical stores of the banner and information on the availability of products in assortment in the physical store within their online channel (see OVS and Louis Vuitton in collaboration with Foresquare). According to consumers' perceptions of online integration, this method of integration can moderate the negative effect of unavailability of products in the online assortment (Bendoly et al., 2005).

Despite the optimistic view about the integration between channels, the emerging trends and positive technological changes, retailers perceive the digital channel as a great challenge to interface with in order to succeed in the new competitive environment and some of them have doubts about the future of digital channels. While some scholars support the thesis of the complementarity of the different channels with the online channel that provides additional information to consumers, reducing research costs and providing a wider range of products (Wallace, Giese \& Johnson, 2004; Herhausen et al., 2015), others believe that one channel replaces another, giving rise to the so-called cannibalization phenomenon between channels (Falk, Schepers, Hammerschmidt \& Bauer, 2007). Furthermore, some retailers believe that the adoption of an omnichannel strategy can increase the complexity of managing corporate operations and in particular supply chain management. As far as operational management is concerned, an omnichannel approach requires huge investments in technologies (Herhausen et al., 2015) and in order to build a successful omnichannel strategy, retailers will have to involve qualified IT personnel (Frazer \& Stiehler, 2014). Furthermore, and particularly in the fashion sector, companies will have to adopt advanced warehouse management systems in order to keep track of the inventory at all times and satisfy customer demand with prompt and timely deliveries (Zhang et al., 2010 ), which requires not only skill, but also a wide-ranging financial investment (Herhausen et al., 2015). Retailers are afraid that their consumers might be disappointed by the lower level of service, different pricing and assortment strategies that the online channel could probably offer (Verhagen \& Van Dolen, 2009; Zhang et al., 2010). For these reasons, some researchers believe that on-offline integration is a "zero-sum game", where the advantages in one channel are offset by the disadvantages in another channel (Falk et al., 2007). The integration between traditional channels and the online channel, from an operational point of view, is however able to produce synergies that reduce the costs of online operations. Once the risk of channel conflict has been avoided, companies could benefit from on-offline integration in four main areas: cost reduction, greater differentiation through the introduction of value-added services, improved relations with consumers and their loyalty to the retailer, geographical and product extension of the market in which the retailer operates (Kumar, Eidem \& Noriega Perdomo, 2012). 


\subsubsection{Innovation versus Tradition}

The digital revolution and digital disruption have "forced" fashion and luxury brands to redesign their internal and external processes by giving more and more importance to the virtual channel in which it is easier today to intercept those who buy fashion and luxury. This allowed fashion retailers to improve the entire corporate image with respect to more traditional actors while maintaining the values of their history and their tradition. Therefore, the digital must be considered as an enabler of the value and image of the brand and in the future fashion and luxury will become synonyms of digital.

The presence of fashion companies in the online channel is far from being perceived in the recent past. In fact, the American designer Donna Karan, in 1997, forbade photographers present at her fashion shows to publish photos on the Internet. For many years, excellent fashion and luxury brands have experienced the advent of digitalization and information technologies with skepticism, so much so that they accuse the Internet and new digital media of being cold, aseptic, vulgar and advocating the democratization of consumption (Grand Union Italy, 2016). Digital innovations found obstacles in the fashion sector, e-commerce was seen as a channel away from the logic of experience proposed by the fashion industry and that had little to do with the warmth and sensory experience that fashion guaranteed through tactile stimuli, visual, olfactory usable within physical boutiques, impossible to reproduce online (Grand Union Italia, 2016). The fashion and luxury sector therefore remained strongly anchored to the physical store that allowed the creation of a unique experience for consumers through contact with products and in store marketing levers controlled by fashion retailers (merchandise layout, architecture, colors, lights and sounds).

With the new Millennium, doubts about digital and the web gave way to a digital orientation. The fashion and luxury brands began a slow approach to the online channel, adapting the online channel to traditional offline concept stores. The disruptive rise of the Internet, mobile and smartphones together with the widespread connectivity of online users who wanted to participate actively in the purchasing process has "forced" fashion companies to invest in digital (Scipioni, 2005). Fashion brands began to focus more on their web pages, to communicate a coherent image, to introduce innovative services: virtual mannequins and dressing rooms, online salespeople, 3D technologies, click \& collect, e-commerce sites, social networks and mobile apps. They then created wishlists, started sharing the image of a garment on social networks or contacting customer service via live chat. Today, fashion retailers are beginning to extend their digital presence through fashion apps and Facebook, Instagram and Pinterest pages where companies publish photos and direct videos of new collections, fashion shows and backstage with the aim of creating a story telling and involving consumers in the world of the brand. Thus, a challenge to exclusivity opens up.

However, fashion shoppers moving between online and offline, still want to see, hear, touch and try the product and immerse themselves in the atmosphere of the store (Rosenblum \& Kilcourse, 2013). In the fashion and luxury sector, the physical store will continue to play a primary role. The digital disruption has the potential to completely transform this sector leading it to relate with the consumer in increasingly innovative ways full of experience, charm, empathy and curiosity.

\subsubsection{Optimization of Business Processes}

In the early stages, the transition from a multichannel to an omnichannel approach involves organizational and operational changes: for example, it involves managing the returns, the reverse logistics and the return policies (no longer post-sales service but an integral part of the purchasing process itself). The share of online returns is higher than offline as consumers do not have the opportunity to touch the product before making a purchase (Grewal, Iyer \& Levy, 2004). The omnichannel approach therefore requires greater attention to managing the reverse flow of the supply chain since the customer returns an order he/she had made online to the point of sale. Since the online assortment is wider than the offline one, the customer is more likely to return a product that is not normally present in the physical store. The design of return policies is of great importance, to find the right balance between cost efficiency and the highest possible level of service (Bell et al., 2013). An efficient return system reduces transport, inventory and inventory costs (Wallace et al., 2004). In e-commerce also the return logistics is strategic: it is an element of reassurance with respect to any risks associated with online purchases (Oh et al., 2012; Bell et al., 2013; Brynjolfsson et al., 2013; Piotrowicz \& Cuthbertson, 2014; Herhausen et al., 2015). Many fashion retailers are now adopting in-store returns of purchases made on the digital channel according to multiple ways of returning items: made at the store, by post or through a locker. In addition to return policies, retailers must deal with and manage demand fulfillment activities, that is all those operational and strategic activities that allow them to evade customer demand as well as all storage and transportation activities. Therefore, shipping services (click-and-collect, home delivery of online orders and in-store orders, 
shipping to pick-up points or automatic lockers), logistics (return logistics, systems of integrated assortment, use of online returns such as assortment, packaging in point-of-sale of orders made via click-and-collect), sales tools (possibility to see the contents of packages, tablet as support for sales in stores), the promotional activities to encourage the use of channels (financial incentives for the combination of channels, consistency of prices, store locator on the website, online information about the availability of products in point of sale by QR code or app), measurements of business performance (monitoring of additional online sales) and all the retail mix levers implemented in the various integrated channels (Zhang et al., 2010).

\subsubsection{Technology: Investments and Implementation of Omnichannel Fashion Retailing Operational Tools}

In order to build a successful omnichannel strategy, retailers will have to allocate significant resources to technological investments and include qualified IT personnel in the company to re-engineer business processes (Frazer \& Stiehler, 2014; Herhausen et al., 2015). For example, retailers in the fashion world should develop advanced warehouse management systems in order to keep track of the inventory at all times and satisfy customer demand through fast and punctual deliveries (Zhang et al., 2010). Furthermore, the literature suggests that technology may not always respond adequately to the expectations of retailers and consumers (DeSanctis \& Poole, 1994). For this reason, it is important that retailers ensure that the technology is well tested and properly developed before being implemented in order to prevent consumers from running into technical problems that could raise a wall between consumers and retailers.

The challenge remains the integration of physical and digital processes. The physical store, in any case, remains a fundamental touch point in the fashion sector. In the new context, it is essential for retailers to renew their concept stores by implementing innovative in-store technologies so that the physical point of sale can evolve from a logistics center to an experiential place. The challenge for the fashion and luxury sector is precisely to build an omnichannel approach that does not penalize experience, to bring the consumer closer to the brand in a more sophisticated, engaging, complete way, offering them a "seamless" customer experience.

The digital technologies to be implemented in the store in an omnichannel perspective are different. Among the most implemented we find interactive kiosks and interactive totems, interactive screens and showcases, virtual fitting rooms, digital signage, location-based service and beacon technologies, RFID technology, NFC and $Q R$-code, tablet and personal digital assistant, mobile POS, augmented reality and Google Glass (Rosenblum \& Kilcourse, 2013).

Interactive kiosks are touchscreen totems that allow consumers to independently obtain technical information and product recommendations or to check their availability at the point of sale or in the nearest stores, order the product online and purchase it by paying with card credit directly from the totem, avoiding the queue at the cash desk.

Interactive touchscreen displays allow the customer to view the entire range of retailers in self-service mode.

The virtual fitting rooms are equipped with a display with an invisible video camera behind the mirror, where the customer, positioning himself in front of the mirror, through the use of augmented reality technologies, has the possibility to try the whole assortment, take selfies and share photos and opinions on social networks using QR Code. Famous are the Magic Fitting Room by OVS in the innovative and interactive concept store 2.0 in the flagship store in Milan, the magic mirrors of the Miroglio Group and Rebecca Minkoff's virtual dressing room in the Connected Store Of The Future flagship store in SoHo in New York City.

The Digital Signage is a form of proximity marketing that is of proximity communication of the point of sale through electronic supports such as screens and video projectors that show the multimedia contents, linked to the brand, to consumers. The purposes can be different, from information support on products, to promotions, to educational spots, to weather or traffic information, to persuasive purposes to create digital signage inside the store in order to increase the time spent in point of sale. Other proximity marketing tools can be Location-based service and Beacon technologies, which exploit the physical proximity of the customer to the point of sale. Thanks to the apps downloaded on smartphones and the combined use of Beacon technology, retailers can send notifications, promotional and welcome messages, and personalized offers to their customers via Bluetooth.

By now, all retailers have introduced in the store the RFID (Radio Frequency Identification) and NFC (Near Field Communication) technologies that allow the exchange of data through digital connectivity in wireless mode. The QR-code (Quick Response) is a new version of the traditional bar code, which allows retailers to store a greater amount of data and once scanned by smartphone or mobile devices and retailers can access the contents of the code quickly and easily by providing to the consumer an interactive and more engaging method of communication. Furthermore, the sales staff can be equipped with tablets and other technological supports to 
assist the consumer during the purchase phase (personal digital assistant) favoring more comfortable payment services and solutions (Mobile POS).

To create an even more immersive experience, many retailers are implementing in their physical stores technological devices that make consumers experience augmented reality. For example, OVS introduced Google Glass in order to make shoppers go around the store looking for new products in the range. The digital treasure hunt (gamification) through the experience of augmented reality allows the customer to win a free OVSCard and 200 Glam points that contribute to achieving the benefits provided by the OVS Loyalty program.

The in-store implementation of the several innovative technologies listed above represents a challenge and a turning point in the fashion and luxury sector which, maintaining the centrality of the traditional physical store, opens up to technology and digital to evolve into a world in which the consumer can really feel pampered and gratified both inside the store and in the online channel through a multitude of digital tools at the point of sale that allow him to combine shopping, experience, customization, uniqueness, fun, innovation and tradition.

\subsubsection{Consumer Centricity}

Omnichannel retailing should be understood as the conceptualization of a "seamless" customer experience and the centrality of the consumer is an essential cornerstone of this approach (Agatz, Fleischmann \& Van Nunen, 2008). It is about offering an easy, comfortable and engaging omnichannel shopping experience (Homburg, Jozić \& Kuehnl, 2017). The post-modern consumer has different needs and is looking for products and services that respond to his/her needs in an increasingly personalized way, especially in the fashion and luxury sector. For this reason, omnichannel fashion retailers must meet the needs of their consumers by ensuring a sufficient degree of customization. This can be achieved by omnichannel retailers thanks to the information assets collected from loyalty cards, pos-scanner technologies, as well as direct and continuous contact with the consumer both in the physical channel and in the online channel. Furthermore, the best performing fashion and luxury retailers on the web have been able to communicate to their consumers contents not only related to the products they already knew and loved, but have also been able to create new desires by proposing content related to products not yet known. In fact, consumers are always in a hurry and retailers must offer them targeted, personalized, short and relevant messages to attract their attention and stimulate new needs and curiosities, positively affecting their involvement. Investing in communication is an essential feature of omnichannel retailers that must involve potential consumers with interesting and always up-to-date content. Using videos and images and storytelling to communicate with consumers and educate them about brand values becomes a necessity for all omnichannel retailers who want to convey a coherent experience to the brand's history and tradition.

In the fashion and luxury sector, it also becomes essential to intercept, engage and retain new generations through innovative and engaging channels, using a language tailored to them. Today's young people, in fact, could be potential customers on which to invest resources right now to intercept the next luxury consumers. Precisely for this reason, many fashion and luxury retailers have tried to involve potential customers through the brand's social channels. The presence on social media represents the possibility for omnichannel retailers to communicate in a two-way with consumers, to create a direct relationship with them, understanding their needs through feedback and reviews on the products purchased, to collaborate with users to develop new products and new concepts, to provide immediate customer support in the event of problems, to involve consumers in games and competitions, to launch promotions or simply to sell their products.

\section{Conclusions, Limitations and Future Research}

Omnichannel retailing is the conceptualization of the complete integration of all channels and the disappearance of the distinction between online and offline (Rigby, 2011; Klosek, 2012; Frazer \& Stiehler, 2014) with significant business implications (Brynjolfsson et al., 2013).

We have tried to clarify the Key Drivers (Q1) and the new challenges (Q2) deriving from the adoption of omnichannel retailing in the fashion and luxury sector (Figure 1). We identified four key factors that stimulated retailers to implement an omnichannel strategy (Q1). Omnichannel fashion retailing is mainly driven by technological innovations, which allow deeper channel integration, cost reduction, wider and easier access to information and large amounts of data, and finally allow retailers to develop more effective and targeted promotions. Furthermore, the development of the Internet in a service dominant perspective has allowed retailers to create greater value for the customer in terms of additional services by offering different services along different channels, from passing from a condition of scarcity of information to a condition of information democracy (Sawhney \& Kotler, 2001). Furthermore, the power of mobile, the increasing penetration of mobile devices and the consequent dependence on smartphones have significantly changed consumer behavior, their decision-making process and in general the way they live and work (Bellini \& Aiolfi, 2017). Retailers have understood the 
relevance of the mobile channel as a sales channel and have begun to manage the mobile with the aim of satisfying the different needs of their consumers according to an omnichannel approach. We tried to understand what could be the new challenges that retailers will have to face when they decide to implement an omnichannel strategy (Q2). According to the academic literature, the ultimate goal of an omnichannel strategy is to create a satisfying and "seamless" customer experience by combining the advantages of the digital and physical channels (Rigby, 2011; Frazer \& Stiehler, 2014). However, online-offline integration brings with it interesting opportunities and at the same time dangerous threats. Among these, we have the possible phenomenon of cannibalization between channels. Furthermore, the adoption of an omnichannel approach requires organizational and operational changes, especially for the supply chain, as well as high investment costs. Omnichannel retailers will have to innovatively manage various activities such as shipping services, logistics, sales tools, return policies, promotional activities, performance measurements and management of the retailing mix levers (Zhang et al., 2010). In addition to organizational changes, omnichannel retailing requires huge investments in technology and the involvement of qualified IT personnel in the re-engineering of their business processes (Frazer \& Stiehler, 2014). Furthermore, for fashion and luxury retailers, it is essential to correctly manage the innovation-tradition combination. In particular, it will be necessary to renew the physical store by implementing innovative in-store technologies that will allow for optimization of the physical channel. Finally, the ultimate goal of responding to consumer demands in the best possible way and thus increasing their level of satisfaction has led omnichannel retailers towards conducting their businesses in a consumer-centric perspective.

The limitations of our work are to be found in the qualitative methodology with which we conducted the research. The theoretical framework is not generalizable. Our study, however, wants to be a first investigation on the new omnichannel retailing paradigm in the fashion and luxury sector. Future research will explore the omnichannel fashion retailing paradigm by considering additional factors not covered in our theoretical framework as well as other emerging challenges that omnichannel retailers will face in the coming years. Furthermore, we commit ourselves to test our theoretical framework with a quantitative analysis and we will try to decline the omnichannel approach in other sectors.

\section{References}

Agatz, N. A., Fleischmann, M., \& Van Nunen, J. A. (2008). E-fulfillment and multi-channel distribution-A review. European Journal of Operational Research, 187(2), 339-356. https://doi.org/10.1016/j.ejor.2007.04.024

Aiello, G., \& Donvito, R. (2006). L'evoluzione del concetto di lusso e la gestione strategica della marca. Un'analisi qualitativa delle percezioni sul concetto, sulla marca e su un prodotto di lusso. In 5th International Congress Marketing trends, Venezia.

Altagamma. (2018). Consumer and retail insight 2017, Milano.

Armstrong, K., \& Rutter, C. (2017). Exploring the enigma of the happiness construct in phygital fashion experiences. Advanced fashion technology and operations management, 220-233. https://doi.org/10.4018/978-1-5225-1865-5.ch009

Baxendale, S., Macdonald, E. K., \& Wilson, H. N. (2015). The impact of different touchpoints on brand consideration. Journal of Retailing, 91(2), 235-253. https://doi.org/10.1016/j.jretai.2014.12.008

Beck, N., \& Rygl, D. (2015). Categorization of multiple channel retailing in Multi-, Cross-, and Omni-Channel Retailing for retailers and retailing. Journal of Retailing and Consumer Services, 27, 170-178. https://doi.org/10.1016/j.jretconser.2015.08.001

Bell, D. R., Gallino, S., \& Moreno, A. (2013). Inventory showrooms and customer migration in omni-channel retail: The effect of product information.

Bellini, S., \& Aiolfi, S. (2017). The impact of mobile device use on shopper behaviour in store: An empirical research on grocery retailing. International Business Research, 10(4), 58. https://EconPapers.repec.org/RePEc:ibn:ibrjnl:v:10:y:2017:i:4:p:58-68

Bendoly, E., Blocher, J. D., Bretthauer, K. M., Krishnan, S., \& Venkataramanan, M. A. (2005). Online/in-store integration and customer retention. Journal of Service Research, 7(4), 313-327. https://doi.org/10.1177/1094670504273964

Brynjolfsson, E., Hu, Y. J., \& Rahman, M. S. (2013). Competing in the age of omnichannel retailing. MIT Sloan Management Review, 54(4), 23.

Christensen, C. M. (2006). The ongoing process of building a theory of disruption. Journal of Product 
Innovation Management, 23(1), 39-55. https://doi.org/10.1111/j.1540-5885.2005.00180.x

Desai, P., Potia, A., \& Salsberg, B. (2012). Retail 4.0: The future of retail grocery in a digital world. Asia Consumer and Retail Practice, 1-67.

Desanctis, G., \& Poole, M. S. (1994). Capturing the complexity in advanced technology use: Adaptive structuration theory. Organization Science, 5(2), 121-147. https://doi.org/10.1287/orsc.5.2.121

Dubois, B., \& Duquesne, P. (1993). The market for luxury goods: Income versus culture. European Journal of Marketing, 27(1), 35-44. https://doi.org/10.1108/03090569310024530

Fairchild, A. M. (2014). Extending the network: Defining product delivery partnering preferences for omni-channel commerce. Procedia Technology, 16, 447-451. https://doi.org/10.1016/j.protcy.2014.10.111

Falk, T., Schepers, J., Hammerschmidt, M., \& Bauer, H. H. (2007). Identifying cross-channel dissynergies for multichannel service providers. Journal of Service Research, 10(2), 143-160. https://doi.org/10.1177/1094670507306683

Frazer, M., \& Stiehler, B. E. (2014). Omnichannel retailing: The merging of the online and off-line environment. In Global Conference on Business \& Finance Proceedings, Institute for Business \& Finance Research, $9(1)$, 655.

Grand Union Italia. (2016). Digital Megatrends in the Fashion Market.

Grewal, D., Iyer, G. R., \& Levy, M. (2004). Internet retailing: enablers, limiters and market consequences. Journal of Business Research, 57(7), 703-713. https://doi.org/10.1016/S0148-2963(02)00348-X

Herhausen, D., Binder, J., Schoegel, M., \& Herrmann, A. (2015). Integrating bricks with clicks: retailer-level and channel-level outcomes of online-offline channel integration. Journal of Retailing, 91(2), 309-325. https://doi.org/10.1016/j.jretai.2014.12.009

Homburg, C., Jozić, D., \& Kuehnl, C. (2017). Customer experience management: toward implementing an evolving marketing concept. Journal of the Academy of Marketing Science, 45(3), 377-401. https://doi.org/10.1007/s11747-015-0460-7

Kapferer, J. N. (2017). Lusso: Nuove sfide, nuovi sfidanti. Franco Angeli, Milano

Keller L.K. (2008). Managing the growth tradeoff: challenges and opportunities in luxury branding. The Journal of Brand Management, 16, pp. 290-301. https://doi.org/10.1057/bm.2008.47

Klosek, N. (2012). Creating the Omni-Channel. Dealerscope, 54(11), 1-4.

Kumar, S., Eidem, J., \& Noriega, P. D. (2012). Clash of the e-commerce titans: A new paradigm for consumer purchase process improvement. International Journal of Productivity and Performance Management, 61(7), 805-830. https://doi.org/10.1108/17410401211263872

Lazaris, C., \& Vrechopoulos, A. (2014). From multi-channel to "omnichannel" retailing: review of the literature and calls for research. In the 2nd International Conference on Contemporary Marketing Issues (ICCMI).

Lewis J., Foster C. \& Whysall P. (2013). Understanding the issues associated with going multi-channel: preliminary findings from an exploratory study in the UK retail sector. In the 17th EAERCD conference.

Mccormick, H., Cartwright, J., Perry, P., Barnes, L., Lynch, S., \& Ball, G. (2014). Fashion retailing-past, present and future. Textile Progress, 46(3), 227-321. https://doi.org/10.1080/00405167.2014.973247

Neslin, S. A., Grewal, D., Leghorn, R., Shankar, V., Teerling, M. L., Thomas, J. S., \& Verhoef, P. C. (2006). Challenges and opportunities in multichannel customer management. Journal of Service Research, 9(2), 95-112. https://doi.org/10.1177/1094670506293559

Neslin, S. A., Jerath, K., Bodapati, A., Bradlow, E. T., Deighton, J., Gensler, S., \& Verhoef, P. C. (2014). The interrelationships between brand and channel choice. Marketing letters, 25(3), 319-330. https://doi.org/10.1007/s11002-014-9305-2

Oh, L. B., Teo, H. H., \& Sambamurthy, V. (2012). The effects of retail channel integration through the use of information technologies on firm performance. Journal of Operations Management, 30(5), 368-381. https://doi.org/10.1016/j.jom.2012.03.001

Osservatorio Ecommerce B2C Netcomm Politecnico di Milano. (2017). XI edizione del Netcomm eCommerce Forum, Milano.

Pentina, I., \& Hasty, R. W. (2009). Effects of multichannel coordination and e-commerce outsourcing on online 
retail performance. Journal of Marketing Channels, 16(4), 359-374. https://doi.org/10.1080/10466690903188021

Piotrowicz, W., \& Cuthbertson, R. (2014). Introduction to the special issue information technology in retail: Toward omnichannel retailing. International Journal of Electronic Commerce, 18(4), 5-16. https://doi.org/10.2753/JEC1086-4415180400

Rigby, D. (2011). The future of shopping. Harvard Business Review, 89(12), 65-76.

Rosenblum, P., \& Kilcourse, B. (2013) Omni-channel 2013: The long road to adoption.

Sawhney, M., \& Kotler, P. (2001). Marketing in the age of information democracy. Kellogg on marketing, 386-408.

Schmidt, E., \& Cohen, J. (2010). The digital disruption- connectivity and the diffusion of power. Foreign Aff.

Sciandra, M. R. (2014). Communication breakdown? Essays examining attention and distraction in technology mediated consumer communications. Working Paper, University of Pittsburgh. http://d-scholarship.pitt.edu/id/eprint/23867

Scipioni, D. (2005). Net fashion: moda, reti e tecnologie. Cooper.

Shankar, V., \& Balasubramanian, S. (2009). Mobile marketing: a synthesis and prognosis. Journal of interactive marketing, 23(2), 118-129. https://doi.org/10.1016/j.intmar.2009.02.002

Shankar, V., Venkatesh, A., Hofacker, C., \& Naik P. (2010). Mobile marketing in the retailing environment: current insights and future research avenues. Journal of interactive marketing, 24(2), 111-120. https://doi.org/10.1016/j.intmar.2010.02.006

Strang, R. (2013). Retail without boundaries. Supply Chain Management Review, 17(6).

Ström, R., Vendel, M., \& Bredican J. (2014). Mobile marketing: A literature review on its value for consumers and retailers. Journal of Retailing and Consumer Services, 21(6), 1001-1012. https://doi.org/10.1016/j.jretconser.2013.12.003

Verhagen, T., \& Van Dolen, W. (2009). Online purchase intentions: A multi-channel store image perspective. Information \& Management, 46(2), 77-82. https://doi.org/10.1016/j.im.2008.12.001

Verhoef, P. C., Kannan, P. K., \& Inman, J. J. (2015). From multi-channel retailing to omni-channel retailing: introduction to the special issue on multi-channel retailing. Journal of retailing, 91(2), 174-181. https://doi.org/10.1016/j.jretai.2015.02.005

Verhoef, P. C., Neslin, S. A., \& Vroomen, B. (2007). Multichannel customer management: Understanding the research-shopper phenomenon. International Journal of Research in Marketing, 24(2), 129-148. https://doi.org/10.1016/j.ijresmar.2006.11.002

Wallace, D. W., Giese, J. L., \& Johnson, J. L. (2004). Customer retailer loyalty in the context of multiple channel strategies. Journal of retailing, 80(4), 249-263. https://doi.org/10.1016/j.jretai.2004.10.002

Webb, K. L. (2002). Managing channels of distribution in the age of electronic commerce. Industrial Marketing Management, 31(2), 95-102. https://doi.org/10.1016/S0019-8501(01)00181-X

Zhang, J., Farris, P. W., Irvin, J. W., Kushwaha, T., Steenburgh, T. J., \& Weitz, B. A. (2010). Crafting integrated multichannel retailing strategies. Journal of Interactive Marketing, 24(2), 168-180. https://doi.org/10.1016/j.intmar.2010.02.002

\section{Copyrights}

Copyright for this article is retained by the author(s), with first publication rights granted to the journal.

This is an open-access article distributed under the terms and conditions of the Creative Commons Attribution license (http://creativecommons.org/licenses/by/4.0/). 